\title{
Amylin and leptin interaction: role during pregnancy, lactation and neonatal development
}

\author{
Boyle, Christina N ; Le Foll, Christelle
}

\begin{abstract}
Amylin is co-secreted with insulin by pancreatic -cells in response to a meal and produced by neurons in discrete hypothalamic brain areas. Leptin is proportionally secreted by the adipose tissue. Both hormones control food intake and energy homeostasis post-weaning in rodents. While amylin's main site of action is located in the area postrema (AP) and leptin's is located in the mediobasal hypothalamus, both hormones can also influence the other's signaling pathway; amylin has been shown enhance hypothalamic leptin signaling, and amylin signaling in the AP may rely on functional leptin receptors to modulate its effects. These two hormones also play major roles during other life periods. During pregnancy, leptin levels rise as a result of an increase in fat depot resulting in gestational leptin-resistance to prepare the maternal body for the metabolic needs during fetal development. The role of amylin is far less studied during pregnancy and lactation, though amylin levels seem to be elevated during pregnancy relative to insulin. Whether amylin and leptin interact during pregnancy and lactation remains to be assessed. Lastly, during brain development, amylin and leptin are major regulators of cell birth during embryogenesis and act as neurotrophic factors in the neonatal period. This review will highlight the role of amylin and leptin, and their possible interaction, during these dynamic time periods of pregnancy, lactation, and early development.
\end{abstract}

DOI: https://doi.org/10.1016/j.neuroscience.2019.11.034

Posted at the Zurich Open Repository and Archive, University of Zurich

ZORA URL: https://doi.org/10.5167/uzh-181652

Journal Article

Accepted Version

Originally published at:

Boyle, Christina N; Le Foll, Christelle (2020). Amylin and leptin interaction: role during pregnancy, lactation and neonatal development. Neuroscience, 447:136-147.

DOI: https://doi.org/10.1016/j.neuroscience.2019.11.034 


\title{
s Amylin and Leptin interaction: Role During Pregnancy, Lactation and Neonatal Development
}

\author{
Christina N. Boyle and Christelle Le Foll* \\ Institute of Veterinary Physiology, University of Zurich, Winterthurerstrasse 260, 8057 Zurich, Switzerland
}

Abstract-Amylin is co-secreted with insulin by pancreatic $\beta$-cells in response to a meal and neurons in discrete hypothalamic brain areas have been shown to produce amylin. Leptin is proportionally secreted by the adipose tissue. Both hormones control food intake and energy homeostasis post-weaning in rodents. While amylin's main site of action is located in the area postrema (AP) and leptin's is located in the mediobasal hypothalamus, both hormones can also influence the other's signaling pathway; amylin has been shown enhance hypothalamic leptin signaling and amylin signaling in the AP may rely on functional leptin receptors to modulate its effect. These two hormones also play major roles during other life periods. During pregnancy, leptin levels rise as a result of an increase in fat depot resulting in gestational leptin-resistance to prepare the body for the metabolic needs during the fetal development. Leptin levels decrease rapidly during the post-partum period and remaining elevated levels could predispose to post-partum depression. The role of amylin is far less studied during pregnancy and lactation, and amylin levels seem to be elevated during pregnancy relative to insulin. Whether amylin and leptin interact during pregnancy and lactation remains to be assessed. Last, during brain development, amylin and leptin are major regulators of cell birth during embryogenesis and act as neurotrophic factors in the neonatal period. This review will highlight the role of amylin and leptin during these different time periods. $\odot 2019$ IBRO. Published by Elsevier Ltd. All rights reserved.

Key words: leptin, amylin, pregnancy, development, hypothalamus, hindbrain, signaling.

\section{GENERAL INTRODUCTION}

Pregnancy, lactation, and the early postnatal period represent life phases of rapid growth and hormonal fluxes. While classically viewed as satiating and adiposity factors, the pancreatic hormone amylin and

*Corresponding author. Tel: +41-44-635-88 36; fax: +41-44-63589-32.

E-mail addresses: boyle@vetphys.uzh.ch (C. N. Boyle), christelle. lefoll@uzh.ch (C. Le Foll).

Abbreviations: AgRP, agouti-related peptide; AMY, amylin receptor; $A P$, area postrema; ARC, arcuate nucleus of the hypothalamus; $B B B$, blood-brain barrier; CTR, calcitonin receptor; Dil, 1,1'-dioctadecyl-3,3 $, 3^{\prime}, 3^{\prime}$-tetramethylindocarbocyanine perchlorate; DIO, diet-induced obese; DMN, dorsal medial nucleus of the hypothalamus; DR, dietresistant; ERK/MAPK, extracellular-signal-regulated kinase/Mitogenactivated protein kinase; GDM, gestational diabetes mellitus; HFD, high fat diet; hIAPP, human islet amyloid polypeptide (amylin); IBAT, interscapular brown adipose tissue; IL-6, interleukin-6; LDTg, lateral dorsal tegmental nucleus; Lepr-b, leptin receptor $b ; \mathrm{LH}$, lateral hypothalamus; LPBN, lateral parabrachial nucleus; MC4 receptor, melanocortin-4-receptor; NPY, neuropeptide Y; NTS, nucleus of the solitary tract; PI3K, phosphoinositide-3 kinase; POA, preoptic area; POMC, pro-opiomelanocortin; pSTAT3, phosphorylated signal transducer and activator of transcription 3; PVN, paraventricular nucleus of the hypothalamus; RAMP, receptor activity modifying protein; TIP39, tuberoinfundibular peptide of 39 residues; $\mathrm{VMH}$, ventral medial hypothalamus (ARC + VMN); VMN, ventral medial nucleus of the hypothalamus; VTA, ventral tegmental area; $\alpha-\mathrm{MSH}$, alpha-melanocyte stimulating hormone. the adipokine leptin are also key players orchestrating changes in the brain and body during these three phases. In this review, we will first summarize the basics of amylin and leptin production and signaling, and how and when these hormones interact. We will then explore recently published and newly hypothesized ways that these hormones cooperate to control physiology, behavior and changes in the brain during the dynamic periods of pregnancy, lactation, and postnatal development.

\section{AMYLIN-LEPTIN INTERACTION AND HYPOTHETICAL MECHANISM OF ACTION IN THE CAUDAL HINDBRAIN AND MEDIOBASAL HYPOTHALAMUS}

Amylin action, receptors and signaling

Amylin is a 37 -amino acid, approximately $4 \mathrm{kDa}$ peptide hormone co-synthetized and co-secreted with insulin by pancreatic $\beta$-cells in response to a meal intake (Ogawa et al., 1990). Amylin is a short-acting peptide with a 15 min half-life (Young, 2005) and binds to heterodimeric receptors composed of the calcitonin receptor (CTR) a or $\mathrm{b}$ and one of the three receptor activity modifying protein (RAMP) 1-3 (Qi et al., 2008; Lee et al., 2016). Together 
CTR and RAMP can form 3 different amylin receptors subtypes AMY1-3 (Hay et al., 2015). RAMP increases the affinity of amylin to CTR (Tilakaratne et al., 2000). Using ${ }^{125}$ I amylin, amylin receptor binding sites have been detected in the area postrema (AP), in the hypothalamus, such as in the arcuate nucleus (ARC), ventromedial nucleus (VMN) and dorsomedial nucleus (DMN) of the hypothalamus, as well as in the ventral tegmental area (VTA) and lateral dorsal tegmental nucleus (LDTg) (Sexton et al., 1994; van Rossum et al., 1994; Hilton et al., 1995; Reiner et al., 2017). Studies using AP lesion and pharmacological approaches have revealed that the AP is peripheral amylin's primary site of action by which it decreases food intake by promoting meal termination (Lutz et al., 2001; Riediger et al., 2001; Riediger et al., 2004). AP amylin-activated neurons project their signal onto the lateral parabrachial nucleus (LPBN), which projects to the central amygdala (Braegger et al., 2014; Potes and Lutz, 2010; Potes et al., 2010b,a). Calcitonin gene-related peptide (CGRP) LPBN neurons are directly innervated by hypothalamic agouti-related peptide (AgRP) neurons (Essner et al., 2017) and respond to direct or indirect amylin activation by decreasing food intake (Carter et al., 2013). At the single cell level in the AP, CTRa seems to be the main subunit present and CTRa + cells are colocalized with RAMP1 and/or RAMP3 (Liberini et al., 2016b). In order to act in nuclei other than in circumventricular organs, such as the AP, amylin has been hypothesized to cross the blood-brain barrier (BBB) (Banks and Kastin, 1998; Banks et al., 1995). In the mediobasal hypothalamus, we have shown using multiple animal models that amylin can directly activate $\mathrm{pERK}$ signaling in pro-opiomelanocortin (POMC) neurons (Lutz et al., 2018). While during the neonatal period, amylin activates $\mathrm{pERK}$ in POMC neurons to enhance $\alpha-\mathrm{MSH}$ fiber projections from the ARC $\rightarrow$ PVN (Lutz et al., 2018), the physiological role of this activation in adult rodents is currently under investigation and our current hypothesis is that amylin-induced pERK in POMC neurons is involved in the regulation of energy expenditure. In other nuclei, such as the VTA, amylin modulates food palatability by favoring fat intake over sucrose intake (Mietlicki-Baase et al., 2017). In the LDTg, injection of amylin or its receptor agonist, salmon calcitonin, decreases body weight, food intake, meal size and motivated feeding (Reiner et al., 2017).

\section{Leptin action, receptors and signaling}

Leptin is a $16 \mathrm{kDa}$ protein hormone that, under weight stable conditions (Gloy et al., 2010), is produced by the adipose tissue proportional to adipose tissue mass and released into the blood stream. Leptin is then transported across the BBB (Bjorbaek et al., 1997; Balland et al., 2014) and acts on leptin receptor b isoform (Lepr-b), which is expressed in neurons in a distributed network throughout the brain (Banks et al., 1996; Caron et al., 2010; Balland et al., 2014). These leptin-sensitive neurons are located in ARC, VMN, DMN, paraventricular nucleus of the hypothalamus (PVN), lateral hypothalamus $(\mathrm{LH})$, preoptic area (POA), VTA and AP/nucleus of the solitary tract (NTS) (Figlewicz, 2016; Friedman, 2016;
Ghamari-Langroudi et al., 2011; Godfrey and Borgland, 2019). Binding of leptin to Lepr-b leads to the recruitment and autophosphorylation of Janus-Activated Kinase 2 (JAK2) and the subsequent phosphorylation of intracellular tyrosine residues (Vaisse et al., 1996; Bjorbaek et al., 1997). Once phosphorylated, pSTAT3 then dimerizes and translocates into the nucleus to regulate gene transcription (Pan et al., 2019). pSTAT3 is a surrogate for JAK/ STAT3 pathway activation. In addition to the JAK/STAT3 signaling pathway, there are also two additional downstream signaling pathways activated by leptin: phosphoinositide-3 kinase (PI3K) and extracellular-factor regulated kinase (ERK) - mitogen-activated protein kinase (MAPK; ERK-MAPK) (Bjorbaek et al., 2001; Niswender et al., 2001). Activation of Lepr-b leads to a number of metabolic processes; pSTAT3 activation in POMC and AgRP/neuropeptide Y (NPY) neurons in the ARC decreases food intake, while PI3K pathway is involved in cell growth, proliferation and death (Chang and Karin, 2001; Vanhaesebroeck et al., 2012). Importantly, in the rodent, leptin functions as a neurotrophic factor during the pre-weaning period (see paragraph below), whereas after pathway formation is complete (postweaning), leptin serves to regulate energy homeostasis.

\section{Synergistic interaction between amylin and leptin}

Interaction in the hypothalamus. More than 10 years ago, Roth et al. were the first to report that amylin restored leptin responsiveness in diet induced obese (DIO) rats and obese humans (Roth et al., 2008; Trevaskis et al., 2008). Together amylin and leptin induced a greater decrease in body weight, food intake and fat deposition, as well as an increase in energy expenditure, than amylin or leptin alone. In obese rats, amylin pretreatment partially restored leptin-induced pSTAT3 in the VMN but not in the ARC (Roth et al., 2008). In lean rats, amylin and leptin synergistically activated PSTAT3 and increased leptin binding in the ARC and VMN (Turek et al., 2010). The crucial role of amylin in enhancing leptin signaling was further confirmed using amylin KO mice whereby leptin induced-pSTAT3 and leptin's lowering effect on body weight were attenuated (Turek et al., 2010). Peripheral amylin injection also increased POMC mRNA expression in rats (Roth et al., 2006) and inhibition of the melanocortin 4 receptor prevented amylin-induced inhibition of feeding and the increase of interscapular brown adipose tissue (iBAT)induced thermogenesis ( $\mathrm{Li}$ et al., 2019). These results suggest a central role of POMC neurons in mediating amylin's actions but whether leptin is also involved in enhancing these effects remains to be determined.

To uncover the mechanism by which amylin is able to enhance leptin signaling, primary neuron, astrocyte and microglial cell culture were exposed to amylin and among all cytokines, interleukin-6 (IL-6) production was increased in microglia only. The role of IL-6 in mediating amylin's action was confirmed by injecting anti-IL- 6 antibody in the third ventricle to neutralize endogenously produced IL-6. This intervention completely inhibited amylin's enhancing effect on leptin-induced pSTAT3 in 
the VMN in rats (Le Foll et al., 2015). The exposure of primary neurons to IL- 6 for 4 days increased Lepr-b mRNA expression and using $\mathrm{Ca}^{2+}$ imaging, it restored the responsiveness to leptin of primary neurons harvested from leptin-resistant DIO rats (Larsen et al., 2016). Thus, we hypothesized that amylin acts on microglia to produce IL-6 which then binds to its neuronal receptor that is composed of gp130. IL-6 activated gp130 is then able to coactivate pSTAT3 with leptin (Le Foll et al., 2015). Following the depletion of the CTR subunit of the amylin receptor heterodimer in the ventromedial hypothalamus $(\mathrm{VMH}=\mathrm{ARC}+\mathrm{VMN})$ using an AAV CTR shRNA, dietresistant (DR) rats, which display normal leptin signaling, have reduced $A R C$ and $V M N{ }^{125}$ l leptin binding and leptininduced pSTAT3 (Dunn-Meynell et al., 2016). CTR VMH depletion increased body weight, food intake and fat pads in chow and high fat diet (HFD)-fed DR rats as compared to scrambled-AAV injected controls. Thus, endogenous amylin signaling is necessary for the maintenance of energy homeostasis and is required for full leptin signaling (Dunn-Meynell et al., 2016). More recently, the depletion of Lepr-b in CTR neurons in mice drastically increased food intake leading to an obese phenotype without altering glucose tolerance (Pan et al., 2018). The transcriptomic analysis of CTR + neurons in the WT and depleted mice revealed that AgRP and NPY mRNA were highly enriched in the hypothalamus whereas POMC was also detected but at a much lower level (Campbell et al., 2017; Pan et al., 2018).

Interaction at the level of $A P$. Several pieces of recent evidence support the notion that amylin and leptin not only interact at the level of the hindbrain, but might also form an interdependent relationship, expanding on the initial observations that amylin unidirectionally potentiates leptin action. $\mathrm{Db} / \mathrm{db}$ mice, which lack functional leptin receptors, have a reduced anorectic response to amylin, do not mount an amylin-induced Fos response in the $A P$, and have reduced CTR density in the AP (Duffy et al., 2018). Single-cell analysis of amylin-activated AP neurons demonstrated that such neurons not only express all amylin receptor components (CTR and RAMPs), but also Lepr-b mRNA (Liberini et al., 2016b). Amylin and leptin were also shown to depolarize the same dissociated AP neurons (Smith et al., 2016). Together these data suggest that amylin and leptin might target the same population of first-order neurons in the AP, and that co-activation of these neurons is required for amylin to induce changes in ingestive behavior and accumulation of Fos protein in AP neurons.

Limitations of the interaction. The key to understanding the mechanism of amylin and leptin's interaction may lie within the limitations of this synergy. Cumulating evidence suggests that a certain level of leptin signaling is necessary for amylin to promote leptin sensitivity. For example, extremely obese rats do not exhibit amylin-induced leptin sensitivity, though they are still responsive to amylin alone (Trevaskis et al., 2010; Trevaskis et al., 2016). Even after significant weight loss by calorie restriction, the once obese rats show no further reduction in body weight when amylin and leptin are given together (Trevaskis et al., 2016); the authors proposed that neither leptin alone nor in combination with amylin could overcome the strong orexigenic drive produced by prolonged caloric restriction. We, in fact, previously observed this phenomenon, when rats restricted to $80 \%$ of ad libitum food intake were non-responsive to amylin's satiating effect (Boyle et al., 2011). Together these observations suggest that amylin's action to induce satiation or potentiate leptin signaling is least effective in instances of absent or low leptin signaling, such as genetic leptin- or Lepr-deficiency, extreme obesity, or following chronic food restriction (Boyle and Lutz, 2011; Boyle et al., 2011; Eiden et al., 2002; Trevaskis et al., 2016).

\section{LEPTIN AND AMYLIN'S INTERACTION DURING PREGNANCY AND LACTATION}

\section{Changes in leptin sensitivity during pregnancy and lactation}

Pregnancy and lactation are two metabolically dynamic periods of a female's life when both the levels of and receptivity to sex and metabolic hormones are changing rapidly. The first and second trimesters of human pregnancy are characterized as anabolic, during which the body prepares for the metabolic demands of late pregnancy and lactation by increasing maternal fat deposition (Villar et al., 1992). Pregnant women exhibit hyperphagia, insulin resistance and hyperinsulinemia, and mild hyperglycemia to ensure transfer of nutrients to the growing fetus (Zeng et al., 2017). From the third trimester, a switch to a catabolic state accelerates the breakdown of fat depots, mobilizing the energy substrates required for late stages of fetal development and lactation (Knopp et al., 1970; Herrera, 2000).

A natural consequence of increased fat deposition during pregnancy is the rise in circulating leptin. In pregnant women and female rats, leptin levels rise during the first and second trimesters and peak in the late second or early third trimester (Hardie et al., 1997; Seeber et al., 2002). Under non-pregnant conditions, such an increase in leptin would signal the brain to reduce food intake and increase energy expenditure. During pregnancy, however, a state of leptin resistance develops to further promote maternal hyperphagia and weight gain, which are essential for fetal growth and development. Ladyman, Grattan and colleagues have extensively characterized the time course and mechanisms underlying the development of leptin resistance in pregnant rat and mouse dams (Reviewed in Ladyman et al., 2010). A rodent pregnancy can last from 21 to 23 days, and though still responsive to exogenous leptin on gestational day 7 , rat dams do not reduce their food intake on gestational day 14 , suggesting a state of leptin insensitivity (Ladyman and Grattan, 2004). Their data suggest that several factors contribute to gestational leptin resistance, including reduced STAT3 activation in first-order ARC and VMN neurons (Ladyman and Grattan, 2004), reduced Lepr-b expression in the VMN (Ladyman and Grattan, 2005), reduced responsiveness of the downstream melanocortin system in both first-order and second-order 
nuclei, such as the PVN (Ladyman et al., 2009, 2016), and possibly reduced transport of leptin into the brain. Unlike in obesity-induced leptin resistance, however, these modifications are not thought to be caused by gestational hyperleptinemia per se (Augustine et al., 2019). This notion is supported by the fact that gestational leptin levels are typically lower than the leptin levels required to induce leptin resistance, and that gestational leptin resistance occurs close to the same time as when leptin levels are significantly increasing, suggesting that leptin resistance occurs in parallel to rising leptin levels, rather than being a consequence of them (Augustine et al., 2019; Ladyman and Grattan, 2004).

Twenty-four hours after delivery, leptin levels dramatically fall below the level of non-pregnant control women, and then progressively increase during the next 6 postpartum months (Lage et al., 1999). As this rapid, initial drop in leptin occurs before the reduction of maternal fat depots, it is likely that this drop reflects the loss of the placenta, which is also a primary source of leptin during pregnancy (Masuzaki et al., 1997). A recent study showed an interesting association between leptin levels in the first $48 \mathrm{~h}$ postpartum and risk for postpartum depression. Chinese women reporting depressive symptoms at 3 months postpartum had significantly higher leptin levels, as well as BMI (Chen et al., 2016), suggesting that early postpartum leptin levels could be used as a biomarker to predict risk of developing postpartum depression. The time course of regaining central leptin sensitivity following birth has not been exhaustively studied, however, one studied showed that 9 weeks after weaning pups, mouse dams exhibit both an anorectic response and increased hypothalamic PSTAT3 following leptin treatment that are similar to the effects observed in virgin female mice (Ladyman et al., 2018).

\section{Role of pancreatic amylin during pregnancy and lactation}

Whether the metabolic actions of amylin change during pregnancy is far less investigated than leptin. Though fasting plasma amylin levels were not different, it was shown that pregnant women have elevated amylin in response to an oral glucose load compared to nonpregnant women (Kautzky-Willer et al., 1997). Whether the pregnant women were normal glucose tolerant or had gestational diabetes mellitus (GDM) did not further influence these elevated amylin levels. Pregnancy also resulted in an increase in the amylin-to-insulin cosecretion factor (Kautzky-Willer et al., 1997); the authors hypothesized that increased amylin secretion relative to insulin might counteract the effects of gestational hyperinsulinemia, thus acting as a safeguard against hypoglycaemia, but it should be noted that the physiological or pathophysiological relevance of altered amylin-to-insulin ratio is generally unknown. Amylin was also observed in human and rat placenta, and its expression was decreased by food restriction, suggesting a potential role for amylin in placental metabolic function (Caminos et al., 2009).

While we know that circulating amylin levels are elevated during pregnancy, similar to leptin, it was not previously investigated whether hyperamylinemia also results in reduced amylin sensitivity. According to the hypothesis put forth by Krautzky-Willer and colleagues, increased amylin might serve as an important protective mechanism against hypoglycemia in the face of gestational hyperinsulinemia, so unlike leptin, a reduction in amylin sensitivity would be counterproductive. In fact, we have recently observed that during mid-gestation, rat dams treated with acute exogenous amylin reduce their food intake to approximately $40 \%$ of their baseline food intake (unpublished observations), which is consistent with the satiating effect observed in healthy male rats (Braegger et al., 2014; Duffy et al., 2018). Preserved amylininduced satiation during pregnancy suggests that loss of amylin sensitivity does not contribute to gestational hyperphagia. These data are also consistent with our previous work showing that, again unlike leptin, hyperamylinemia is not equated with amylin resistance — both obese male rats maintained on HFD, and lean rats made hyperamylinemic via chronic amylin infusion still reduced food intake in response to acute peripheral treatment with amylin (Boyle et al., 2011).

Peripheral amylin levels appear to decrease in the postpartum period. There are data showing that amylin returns to pre-partum levels $12-16$ weeks after delivery in both healthy women and those diagnosed with GDM (Kautzky-Willer et al., 1997). However, another study showed that fasting amylin levels were twofold higher in women diagnosed with GDM than in healthy controls at 6 weeks postpartum (Kinalski et al., 2004). It is presently unclear whether these differential effects are merely related to the time of amylin measurement, or if elevated early postpartum amylin levels might actually be indicative of metabolic disruption (Kinalski et al., 2004). A recent study demonstrated that mice transgenic for human amylin (hIAPP mice) are prone to developing diabetes during and after pregnancy resulting from beta cell stress (Gurlo et al., 2019). While rodent amylin is soluble and nonaggregating (Huang et al., 2007), human and cat amylin is amyloidogenic, forming toxic oligomers that eventually cause beta cell destruction and are present in type 2 diabetes. Rodents typically do not develop gestational diabetes that is comparable to the human condition (Plows et al., 2017), however hIAPP mice present a useful model of beta cell dysfunction that recapitulates several characteristics of human GDM (Gurlo et al., 2019). Whether increased expression of amylin or the formation of cytotoxic amyloid deposits in pancreatic beta cells contributes to human cases of GDM has not been determined (Gurlo et al., 2019).

\section{Role of central amylin during lactation}

Interestingly, Dobolyi and colleagues showed that in postpartum rat dams, amylin expression in the brain is remarkably upregulated in the POA of the hypothalamus (Dobolyi, 2009; Szabo et al., 2012), a critical center for the initiation and maintenance of maternal behavior. Amylin levels do not increase until day 1 postpartum, and remain elevated up until day 23 , when their pups were weaned (Szabo et al., 2012). Whether and at what rate 
amylin levels in this brain area are reduced after weaning was not studied. If mother rats are deprived of their pups following birth, amylin levels in the POA are similar to those observed in virgin female rats (Dobolyi, 2009). Nulliparous rats that were maternally sensitized, however, also exhibited increased amylin mRNA, demonstrating the importance of pup exposure to this change in central amylin levels (Szabo et al., 2012). This idea was further confirmed by data showing that approximately $85 \%$ of amylin-producing neurons in the POA co-express Fos in response to pup exposure (Szabo et al., 2012).

The driver behind this significant increase in amylin production in the maternal brain has not been completely determined. Ovariectomy of virgin rats does not lead to induction of amylin in the POA, suggesting that reduced levels of ovarian hormones themselves (as occurs at the time of parturition) do not drive the increase in amylin per se (Szabo et al., 2012). However, since the hormonal status of a newly primiparous female and an ovariectomized virgin female rat are not identical, excluding a role of sex hormones in postpartum amylin production is perhaps premature. Dobolyi and colleagues have proposed that the tuberoinfundibular peptide of 39 residues (TIP39) could be a regulator of amylin expression levels. TIP39-producing neurons in the posterior intralaminar complex of the thalamus are activated by pup suckling (Cservenak et al., 2010) and may contribute to suckling-induced prolactin release (Cservenak et al., 2013). These neurons send fibers to numerous hypothalamic nuclei, including the POA (Dobolyi et al., 2003; Dobolyi, 2011), which expresses postpartum amylin. In addition to the amylin-expressing cells in the POA described by Dobolyi, we have also observed amylin immunoreactivity in the subfornical organ, supraoptic nucleus, and ARC of lactating rat dams (unpublished observations). The expression pattern of hypothalamic amylin-producing cells is notably similar to that of prolactin-sensitive cells (Brown et al., 2010; Kamesh et al., 2018). Whether the increase in central amylin expression is related to the increasing prolactin levels, which peak at the time of birth and in response to suckling stimuli, has not been investigated.

\section{Do amylin and leptin interact during pregnancy and lactation?}

To date, the presence of an interaction between leptin and amylin during pregnancy and lactation has not been directly investigated. Unlike leptin resistance that results from obesity, gestational leptin resistance is an important adaptation to ensure the health of the growing fetus. Thus amylin's potential to restore leptin sensitivity would potentially be disadvantageous in this condition. Interestingly, IL-6 mRNA levels are reduced in the hypothalamus of pregnant mice (Pazos et al., 2013). Given that amylin enhances leptin signaling by increasing hypothalamic IL-6 (Le Foll et al., 2015), a reduction of IL-6 during pregnancy could hypothetically prevent amylin from enhancing central leptin signaling, thus maintaining gestational leptin resistance.

Could alterations in leptin levels and sensitivity also influence central amylin levels in postpartum dams?
Given the huge surge of brain amylin following parturition, perhaps this is related to a leptin insensitive pregnant brain transitioning into a postpartum brain, which is regaining leptin sensitivity? Data from $\mathrm{Li}$ and colleagues, demonstrating that leptin levels appear to influence central amylin expression in non-pregnant female and male mice, provide additional insight into what is regulating these amylin-producing neurons in the brain (Li et al., 2015). Messenger RNA levels of hypothalamic amylin were higher in female mice than in males. Female ob/ob mice, which do not produce leptin and are subsequently obese, had significantly reduced hypothalamic amylin mRNA compared to wild type females, but expressed levels similar to those observed in male wild type and ob/ob mice. When treated with exogenous leptin for three months, ob/ob female mice, but not males, showed elevated levels of hypothalamic amylin mRNA. In DIO mice maintained on HFD for 26 weeks, in which leptin levels are high but leptin sensitivity is low, central amylin expression was decreased in females, but elevated in males. These data suggest that leptin and leptin sensitivity, and potentially female sex hormones, may be critical factors regulating centrally produced amylin. Estrogens are indeed protective against various genetic modifications that promote metabolic disease states, including Lepr deficiency (Mauvais-Jarvis et al., 2017). And while a genetic mutation such as leptin deficiency has clear consequences for central amylin production (Li et al., 2015), it is unknown if a polygenic predisposition for obesity would also influence central amylin expression. Do leptinresistant DIO and leptin-sensitive DR rats exhibit inherent differences in central amylin during lactation? Do differences in central amylin expression dictate the quality of maternal care that a dam provides her pups? Does lactation intensity contribute to central amylin expression? Are differences in central amylin a consequence of or contributors to varying levels of leptin responsiveness? Additional questions, like whether postpartum central amylin levels are altered by maternal leptin levels, obesity or consumption of HFD during pregnancy or lactation, are currently being explored.

\section{AMYLIN AND LEPTIN INTERACTION DURING DEVELOPMENT}

Brain development involves neuronal birth or neurogenesis that is then followed by the migration of these neurons to their target nuclei and finally by the formation of neuronal circuits which involve axonal outgrowth and synaptogenesis (Markakis, 2002; Bouret, 2010a). Amylin and leptin have been shown to modulate these processes (Bouret, 2010b; Johnson et al., 2016; Lutz et al., 2018).

Neurogenesis in brain areas involved in the control of energy metabolism

During embryogenesis. Cells in the mediobasal hypothalamus are born between embryonic day $(E) 11$ and E16 (Ishii and Bouret, 2012; Padilla et al., 2010) with a peak at E12 (Croizier et al., 2010). In the ARC, most of 
the POMC neurons are born between E12-E14 whereas NPY neurons are first detected at E13.5 (Padilla et al., 2010). In the caudal hindbrain, where the AP is located, cell birth during embryogenesis and particularly the role of the different hormones, has been far less studied. However $\mathrm{PHOX} 2 \mathrm{~B}$, a transcription factor that is required for the development of the autonomic nervous system and the birth of noradrenergic neurons, a population onto which amylin signals (Braegger et al., 2014), is already expressed at E14.5 (Gokozan et al., 2016). Furthermore the expression of CTR has been found at E12/13 in the POA, hypothalamus, anterior and posterior pons as well as in the medulla regions (Tolcos et al., 2003). Amylin has also been first detected in pancreatic islet at E12 where its secretion seems to reach a peak at E17 during the fetal period (Rindi et al., 1991; Mulder et al., 1998). Together these data suggest that amylin and its receptor are present embryonically starting at least at E12.

We recently investigated the role of endogenous amylin during embryonic development (Lutz and Le Foll, 2019). Pregnant amylin KO and WT littermate mice were injected with BrdU, a thymidine analog and marker of newly born cells, at E11.5-E12, i.e. the time when amylin has been shown to be secreted and when cells are born in the hypothalamus and in the hindbrain. The quantification of $\mathrm{BrdU}+$ cells in the offspring at postnatal day $(P) 2$ showed that newborn amylin $\mathrm{KO}$ mice have less cells being born in the ARC at E11.5-E12. Interestingly, among the cells being born, the same number of neurons was found in WT and $\mathrm{KO}$, however less microglial cells were born in $\mathrm{KO}$ mice compared to WT. Meanwhile in the VMN, DMN, LH and AP, the number of newly born cells was similar in WT and KO, but, among those cells, less microglia cells were born in the AP of KO mice (Lutz and Le Foll, 2019). Thus, during brain development between day E12 and P2, amylin does not appear to play a role in neurogenesis processes, but it contributes to the birth and the fate of microglial cells in the ARC and AP. Since microglial cells originate from erythrocyte precursors in the yolk sac and migrate to the brain during embryogenesis at E9.5 (Ginhoux et al., 2010; Sousa et al., 2017), whether peripheral amylin affects the migration of these cells to the brain should also be investigated.

Leptin is one of the most studied protein hormones in the context of obesity and the role of metabolic signals in brain development. Even though the mouse embryo presents a very low amount of white adipose tissue, leptin has been measured in mice embryo starting at E14 (Udagawa et al., 2006). Further, it has also been shown that maternal leptin cannot cross the placental barrier (Udagawa et al., 2006), suggesting that leptin produced by the fetus is involved in neurogenesis processes. Lepr-b mRNA has been detected at E12 in the hindbrain and the hypothalamus, with its expression level increasing by 5-10-fold at E14 (Croizier et al., 2016). Further, Lepr-b positive cells are co-expressed with nestin, a neuronal marker, at E14 in mice cerebral cortex (Udagawa et al., 2006). To study the role of leptin in embryonic brain development, WT mice, injected with BrdU from E11 to E18, were treated with leptin at 8 weeks-old and leptin-induced c-Fos was assessed and co-labelled with BrdU + cells to measure the number of neurons responding to leptin that were born between E11 and E18. Mice that were injected at E12 with BrdU presented the highest number of cells positive for both BrdU and leptin-induced c-Fos in ARC, VMN, DMN and LH (Ishii and Bouret, 2012), confirming that E12 is a critical time point during which most of the leptin-sensitive neurons are being born. These findings provide a plausible explanation for an observation made more than 40 years ago showing that ob/ob mice displayed a smaller brain (weight and volume) compared to WT mice (Bereiter and Jeanrenaud, 1979) and that ob/ob mice presented a mild hypocellularity in the ARC and VMN (Garris, 1989). When BrdU was injected between E14 and E16, the number of BrdU + cell in the neuroepithelium in the cortex was reduced in ob/ob mice compared to WT mice; this reduction was prevented when leptin was injected directly into the mice embryos lateral ventricle, further demonstrating the critical role of leptin during embryogenesis (Udagawa et al., 2006). Unfortunately, ob/ob mice neurogenesis was never assessed in other brain areas.

Based on the known interaction between amylin and leptin in adult animals, and the fact that amylin and leptin seem to both contribute to cell birth at E2 (Ishii and Bouret, 2012; Lutz and Le Foll, 2019), we sought to determine if amylin influences the birth of cells that are leptin sensitive. WT and amylin KO mice injected with $\mathrm{BrDU}$ at E12 were assessed for leptin-induced C-Fos at 5 weeks old in in ARC, VMN, LH and DMN. These nuclei have been shown to be sensitive to leptin's action on food intake and energy homeostasis (Bouret, 2017; Park and Ahima, 2015). The same number of BrdU + leptinsensitive cells were quantified in ARC and DMN while in the $\mathrm{VMN}$ and $\mathrm{LH}$, amylin $\mathrm{KO}$ mice displayed a higher number of BrdU + leptin-sensitive cells (Lutz and Le Foll, 2019). Interestingly, the absence of amylin did not decrease the birth of leptin-sensitive cells in the hypothalamus. On the contrary, the absence of amylin even increased the number of leptin-sensitive cells in the $\mathrm{VMH}$ and $\mathrm{LH}$ suggesting a possible counter-regulatory mechanism. To fully assess amylin's neurogenic role, future studies examining amylin KO and WT littermates at earlier and later time-points need to be undertaken. Furthermore, the assessment of apoptosis in these studies was not performed and even though amylin does not affect the number of newly born neurons when assessed at P2 and 5 weeks old, it is possible that cell death was affected and that the overall balance cell birth/death is modulated by amylin during embryogenesis (Dekkers et al., 2013).

At adulthood. Neurogenesis is not limited to the embryonic period but proceeds throughout the entire lifespan in the dentate gyrus of the hippocampus and the olfactory bulb (Duman et al., 2001a,b; Lledo and Valley, 2016). New evidence indicates that hormones such as amylin, leptin, insulin and ghrelin may also enhance adult neurogenesis in different brain areas (Liberini et al., 2016a; Bouret, 2017). The purpose and functional relevance of this adult neurogenesis is still under investigation, but since the brain does not grow in 
size, this process could be part of a renewing mechanism that is probably activated by these hormones. Whether these hormones could change or improve the metabolic characteristics of the newly born cells remain to be determined.

A BrdU pulse was performed at E10.5 in mice and it was observed that the number of BrdU + POMC and $\mathrm{BrdU}+\mathrm{NPY}$ neurons in the ARC decreased by $50 \%$ from 4 weeks old to 12 weeks old lean mice suggesting that half of the neurons are renewed post-natally. No cell renewal was measured at later time points from 8 to 26 weeks old in the ARC. There was no difference in the number of BrdU + cells in the amygdala at any time point, suggesting that cell renewal during adulthood may be restricted to specific brain areas (McNay et al., 2012). By comparison, DIO mice display a lower amount of newly born cells compared to chow-fed mice from 16 to 20 weeks of age, suggesting that nutritional and/or hormonal status affect neurogenesis in the ARC (McNay et al., 2012). Further experiments uncovered that DIO inhibits the differentiation of stem cells into proliferative progenitor-like cells and increases apoptosis. Neurogenesis in adult ob/ob mice was even more reduced than in DIO mice confirming the crucial role of leptin in neurogenic processes at adulthood (McNay et al., 2012). In the hippocampus, chronic leptin administration in adult lean mice increased cell proliferation without altering differentiation or survival rate of these newly proliferated cells; these leptin-induced mechanisms could be involved the improvement of spatial memory and learning that has been shown after leptin injection (Farr et al., 2006; Oomura et al., 2006). More recently, the administration of leptin in the lateral ventricle of adult ob/ob mice enhanced spatial memory when combined with mildexercise and anti-oxidative interventions, supporting the notion that leptin contributes to hippocampus-based plasticity (Yook et al., 2019). In vivo and in vitro mechanistic studies by Garza et al. showed that leptin enhanced adult cell proliferation in the hippocampus by activating pSTAT3 and Akt intracellular signaling pathways (Garza et al., 2008). Whether this is also true in other brain areas still needs to be uncovered.

Amylin also appears to contribute to neurogenesis in the adult brain. In the AP, our group found that acute and chronic amylin treatment upregulates genes, such as NeuroD1, that are involved in cell proliferation and neurogenesis (Liberini et al., 2016a). Amylin's effect on cell birth was explored in lean adult male rats injected with BrdU for 1 week and concomitantly treated with amylin for 4 weeks. Amylin treatment increased the number of BrdU + cells in the AP compared to control-treated rats, and these cells were identified as neurons, suggesting that amylin is able to increase neurogenesis in the AP of adult rats (Liberini et al., 2016a). Investigations into amylin's role in neurodegenerative diseases, such Alzheimer's, has shown that lower amylin plasma levels have been detected in patients presenting mild cognitive impairment and Alzheimer's symptoms. The chronic injection of senescence-accelerated prone mouse with pramlintide, an amylin analog, improved memory and cognition and increased the synaptic marker synapsin 1, suggesting neuroprotective effects of amylin (Adler et al., 2014). Surprisingly, in a rat H19-7 HN cell line, pharmacological concentrations of amylin decreased cell proliferation while leptin had the opposite effect. Furthermore, amylin decreased cell differentiation into neurons while leptin promoted it. The co-treatment of these cells with amylin and leptin had no effect on cell proliferation suggesting that amylin inhibited leptin cell-induced proliferation and differentiation (Moon et al., 2013). This discrepancy with previous studies could be explained by the fact that Moon et al. used human amylin which can aggregate and promote cell death. The in vivo interaction between amylin and leptin on cell proliferation and neurogenic processes has not been assessed yet during adulthood. Whether this could be of interest in the treatment of obesity or neurodegenerative diseases remains to be determined.

\section{Neuronal pathway development during the neonatal period}

Following cell birth, differentiation and migration, neurons develop connections to other neurons located in the same or in other nuclei. This phenomenon takes place during the last week of gestation and during the first 2 weeks of life for a rodent (Bouret, 2017; Bouret and Simerly, 2006), and during the first 6 months of life in humans (Stiles and Jernigan, 2010). These axonal projections develop throughout the brain and since amylin and leptin's primary sites of action are the AP and the ARC, respectively, these specific brain nuclei will be examined here.

Neuronal pathway development from ARC to PVN. Axonal outgrowth from the two major neuronal populations in the ARC, AgRP/NPY neurons and POMC neurons, has been extensively studied. These neurons project mainly to the PVN, LH and the DMN (Baker and Herkenham, 1995; Broberger et al., 1998). Grove et al. (2003) and Nilsson et al. (2005) have shown that axonal projections from AgRP/NPY and POMC neurons develop during the second postnatal week in rats and mice. While immunohistochemistry is commonly used to detect peptides travelling along the axons, the fluorescent tracer Dil, is a robust method for visualizing developing neuronal pathways, independent of neuronal or axonal peptide synthesis, which may change over the period of investigation. Using the Dil technique, it has been shown that ARC $\rightarrow$ $\mathrm{PVN}$ and $\mathrm{ARC} \rightarrow \mathrm{DMN}$ axonal projection reflects the development pattern of AgRP/NPY innervation (Bouret et al., 2004a). At P6, ARC axons projects to the DMN and by $\mathrm{P} 8$ they send input to the PVN and finally by P12 to the LH (Bouret and Simerly, 2004).

Interestingly, leptin blood level surges from P7 to P12 (Ahima et al., 1998) and this peak coincides with the axonal outgrowth that takes place in the ARC. Leptindeficient ob/ob mice present a strong disruption in $\mathrm{ARC} \rightarrow \mathrm{PVN}$ and ARC $\rightarrow$ LH projections that are restored if the mice are injected twice daily with leptin during the first two weeks of neonatal life, but not when injected in adult mice (Bouret et al., 2004b); the same disruption was also found in $\mathrm{db} / \mathrm{db}$ mice (Bouret et al., 2004b). Using $A R C$ explants from neonatal mice, it was shown that the 
activation of pSTAT3 and pERK pathways by leptin seems to be necessary to promote fiber outgrowth. Hence, leptin presents a trophic action that is necessary for the development of the mediobasal hypothalamus, while it assumes its role in the regulation of energy homeostasis after these pathways have completed their development (Ahima and Hileman, 2000; Bouret et al., 2004b; Mistry et al., 1999; Steppan and Swick, 1999). Nonetheless, it needs to be mentioned that naïve adult ob/ob mice, with disrupted ARC projections, are still responsive to leptin injections, and reduce eating as observed in control lean animals (Mistry et al., 1997).

The model of selectively bred DIO and DR rats reflect the polygenic abnormalities of human obesity (Levin et al., 2008). Chow-fed DIO rats are larger but not fatter than DR rats, but on high energy diet, DIO rats gain more weight and eat more than DR rats (Levin and Dunn-Meynell, 2002; Levin et al., 1997). DIO rats have reduced leptin signaling as early as P7 (Patterson et al., 2010; Johnson et al., 2016), and this defect is mostly present in POMC neurons (Johnson et al., 2016). Furthermore, DIO rat neonates have defective ARC $\rightarrow$ PVN projections that persist into adulthood (Bouret et al., 2008); this defect affects the outgrowth of both POMC and AgRP/NPY fibers. When ARC explant form DIO and DR P10 rats are exposed to leptin, only DR explants respond to the trophic action of leptin (Bouret et al., 2008), whereas DIO explants are insensitive due to their inherent leptin resistance that is already present at P10 (Johnson et al., 2016).

Contrary to leptin, baseline blood amylin concentration does not seem to fluctuate postnatally (Abegg et al., 2017). Since amylin modulates leptin signaling, amylin's trophic action was also examined in the mediobasal hypothalamus. RAMP $1 / 3 \mathrm{KO}$ mice, which present deficient amylin signaling, showed a decrease in $\mathrm{ARC} \rightarrow \mathrm{PVN}$ POMC and AgRP/NPY fibers projections, whereas amylin $\mathrm{KO}$ mice only presented a decrease in $\alpha$-MSH fibers in the PVN (Lutz et al., 2018). The depletion of CTR in rat neonates (P4) also only decreased the density of $\alpha-\mathrm{MSH}$ fibers in the PVN. Since in adult animals, amylin is able to activate microglial IL-6 production, which then acts on its neuronal gp130 receptor to enhance leptin-induced pSTAT3 (Le Foll et al., 2015), IL6 KO mice were examined and surprisingly, these mice only presented a decrease in AgRP fiber density in the PVN (Johnson et al., 2016). Our current hypothesis is that during the neonatal stage, amylin acts as a neurotrophic factor directly on POMC neurons during the first two weeks of life to enhance leptin-induced development of fiber projections to the PVN, while amylin may acts indirectly on NPY neurons through IL-6 (Levin and Lutz, 2017). The treatment of DIO neonates with amylin from P0 to P16 restored their $\alpha-\mathrm{MSH}$ and AgRP/NPY fiber development to the PVN and increased leptin signaling at P21. However, despite this pathway correction, amylin treatment during the neonatal period did not protect adult DIO rats against weight gain and leptin resistance (Johnson et al., 2016). In conclusion, amylin and leptin seem to play an important role in the development of the mediobasal hypothalamus, which is critical for the control of energy homeostasis.

Neuronal pathway development from AP to NTS. To assess amylin's neurotrophic properties in the AP, the fluorescent tracer Dil was implanted into the AP of amylin $\mathrm{KO}$ mice at P10 and P60 in order to measure the neurite outgrowth from the AP to the NTS (Abegg et al., 2017). At both ages, the neurite outgrowth was decreased in amylin $\mathrm{KO}$ mice, demonstrating that endogenous amylin seems to be necessary for the promotion of axonal pathway development from AP $\rightarrow$ NTS during the early postnatal period, and that this effect persists into adulthood. Similarly, ob/ob mice presented a decrease in fiber projections from AP $\rightarrow$ NTS at P14, but unlike amylin KO mice, this effect did not persist until adulthood. As discussed above, it has been recently shown that amylin is also produced by neurons in the brain (Li et al., 2015), and whether brain-derived amylin influences these neurotrophic processes also needs to be assessed.

The data and literature reviewed above provide evidence that leptin and amylin, metabolic hormones controlling food intake and body weight, are also key players supporting neural and physiological adaptations that occur during pregnancy, lactation, and postnatal development. We have also presented several unanswered questions related to how these hormones influence each other during these specific phases of life. For instance, the precise function and regulation of centrally produced amylin, notably during lactation but also in non-lactating females and males, remains unknown. What is amylin really doing in the brain? Does it regulate the increased caloric need to support lactation or is its function unrelated to metabolic control? Could neurons in fact be the source of amylin that sensitizes leptin-responsive neurons in hypothalamus? Does central amylin influence the development of leptinregulated neuronal pathways? Is the interaction of amylin and leptin always dependent on amylin-induced IL-6 levels, or might other mechanisms underlie this relationship during phases of development or related to pregnancy and lactation? The answers to these key questions will provide a better understanding of which biological processes amylin and leptin co-regulate during these different developmental phases, and whether alteration of these processes contributes to the development of or protection from obesity.

\section{ACKNOWLEDGEMENTS}

We acknowledge Julia Bayer for her work on amylin action and expression during pregnancy and lactation in rats, and to Thomas A. Lutz for his review of this manuscript.

\section{REFERENCES}

Abegg K, Hermann A, Boyle CN, Bouret SG, Lutz TA, Riediger T (2017) Involvement of amylin and leptin in the development of projections from the area postrema to the nucleus of the solitary tract. Front Endocrinol (Lausanne) 8:324. 
Adler BL, Yarchoan M, Hwang HM, Louneva N, Blair JA, Palm R, Smith MA, Lee HG, et al. (2014) Neuroprotective effects of the amylin analogue pramlintide on Alzheimer's disease pathogenesis and cognition. Neurobiol Aging 35:793-801.

Ahima RS, Hileman SM (2000) Postnatal regulation of hypothalamic neuropeptide expression by leptin: implications for energy balance and body weight regulation. Regul Pept 92:1-7.

Ahima RS, Prabakaran D, Flier JS (1998) Postnatal leptin surge and regulation of circadian rhythm of leptin by feeding. Implications for energy homeostasis and neuroendocrine function. J Clin Invest 101:1020-1027.

Augustine RA, Knowles PJ, Khant Aung Z, Grattan DR, Ladyman SR (2019) Impaired hypothalamic leptin sensitivity in pseudopregnant rats treated with chronic prolactin to mimic pregnancy. J Neuroendocrinol:e12702.

Baker RA, Herkenham M (1995) Arcuate nucleus neurons that project to the hypothalamic paraventricular nucleus: neuropeptidergic identity and consequences of adrenalectomy on mRNA levels in the rat. J Comp Neurol 358:518-530.

Balland E, Dam J, Langlet F, Caron E, Steculorum S, Messina A, Rasika S, Falluel-Morel A, et al. (2014) Hypothalamic tanycytes are an ERK-gated conduit for leptin into the brain. Cell Metab 19:293-301.

Banks WA, Kastin AJ, Maness LM, Huang W, Jaspan JB (1995) Permeability of the blood-brain barrier to amylin. Life Sci 57:1993-2001.

Banks WA, Kastin AJ, Huang W, Jaspan JB, Maness LM (1996) Leptin enters the brain by a saturable system independent of insulin. Peptides 17:305-311.

Banks WA, Kastin AJ (1998) Differential permeability of the bloodbrain barrier to two pancreatic peptides: insulin and amylin. Peptides 19:883-889.

Bereiter DA, Jeanrenaud B (1979) Altered neuroanatomical organization in the central nervous system of the genetically obese (ob/ob) mouse. Brain Res 165:249-260.

Bjorbaek C, Uotani S, da Silva B, Flier JS (1997) Divergent signaling capacities of the long and short isoforms of the leptin receptor. $\mathrm{J}$ Biol Chem 272:32686-32695.

Bjorbaek C, Buchholz RM, Davis SM, Bates SH, Pierroz DD, Gu H, Neel BG, Myers Jr MG, et al. (2001) Divergent roles of SHP-2 in ERK activation by leptin receptors. J Biol Chem 276:4747-4755.

Bouret SG (2010b) Neurodevelopmental actions of leptin. Brain Res 1350:2-9.

Bouret SG (2010a) Development of hypothalamic neural networks controlling appetite. Forum Nutr 63:84-93.

Bouret SG (2017) Development of hypothalamic circuits that control food intake and energy balance. In: Harris RBS, editor. Appetite and Food Intake: Central Control. Boca Raton (FL): CRC Press/ Taylor \& Francis. p. 135-154.

Bouret SG, Simerly RB (2004) Minireview: leptin and development of hypothalamic feeding circuits. Endocrinology 145:2621-2626.

Bouret SG, Simerly RB (2006) Developmental programming of hypothalamic feeding circuits. Clin Genet 70:295-301.

Bouret SG, Draper SJ, Simerly RB (2004a) Formation of projection pathways from the arcuate nucleus of the hypothalamus to hypothalamic regions implicated in the neural control of feeding behavior in mice. J Neurosci 24:2797-2805.

Bouret SG, Draper SJ, Simerly RB (2004b) Trophic action of leptin on hypothalamic neurons that regulate feeding. Science 304:108-110.

Bouret SG, Gorski JN, Patterson CM, Chen S, Levin BE, Simerly RB (2008) Hypothalamic neural projections are permanently disrupted in diet-induced obese rats. Cell Metab 7:179-185.

Boyle CN, Lutz TA (2011) Amylinergic control of food intake in lean and obese rodents. Physiol Behav 105:129-137.

Boyle CN, Rossier MM, Lutz TA (2011) Influence of high-fat feeding, diet-induced obesity, and hyperamylinemia on the sensitivity to acute amylin. Physiol Behav 104:20-28.

Braegger FE, Asarian L, Dahl K, Lutz TA, Boyle CN (2014) The role of the area postrema in the anorectic effects of amylin and salmon calcitonin: behavioral and neuronal phenotyping. Eur $\mathrm{J}$ Neurosci 40:3055-3066.

Broberger C, Johansen J, Johansson C, Schalling M, Hokfelt T (1998) The neuropeptide Y/agouti gene-related protein (AGRP) brain circuitry in normal, anorectic, and monosodium glutamatetreated mice. Proc Natl Acad Sci U S A 95:15043-15048.

Brown RS, Kokay IC, Herbison AE, Grattan DR (2010) Distribution of prolactin-responsive neurons in the mouse forebrain. J Comp Neurol 518:92-102.

Caminos JE, Bravo SB, Garces MF, Gonzalez CR, Cepeda LA, Gonzalez AC, Nogueiras R, Gallego R, et al. (2009) Vaspin and amylin are expressed in human and rat placenta and regulated by nutritional status. Histol Histopathol 24:979-990.

Campbell JN, Macosko EZ, Fenselau H, Pers TH, Lyubetskaya A, Tenen D, Goldman M, Verstegen AM, et al. (2017) A molecular census of arcuate hypothalamus and median eminence cell types. Nat Neurosci 20:484-496.

Caron E, Sachot C, Prevot V, Bouret SG (2010) Distribution of leptinsensitive cells in the postnatal and adult mouse brain. J Comp Neurol 518:459-476.

Carter ME, Soden ME, Zweifel LS, Palmiter RD (2013) Genetic identification of a neural circuit that suppresses appetite. Nature 503:111-114.

Chang L, Karin M (2001) Mammalian MAP kinase signalling cascades. Nature 410:37-40.

Chen C, Gao J, Zhang J, Jia L, Yu T, Zheng Y (2016) Serum leptin level measured $48 \mathrm{~h}$ after delivery is associated with development of postpartum depressive symptoms: a 3-month follow-up study. Arch Womens Ment Health 19:1001-1008.

Croizier S, Franchi-Bernard G, Colard C, Poncet F, La Roche A, Risold PY (2010) A comparative analysis shows morphofunctional differences between the rat and mouse melanin-concentrating hormone systems. PLoS One 5 e15471.

Croizier S, Prevot V, Bouret SG (2016) Leptin controls parasympathetic wiring of the pancreas during embryonic life. Cell Rep 15:36-44.

Cservenak M, Bodnar I, Usdin TB, Palkovits M, Nagy GM, Dobolyi A (2010) Tuberoinfundibular peptide of 39 residues is activated during lactation and participates in the suckling-induced prolactin release in rat. Endocrinology 151:5830-5840.

Cservenak M, Szabo ER, Bodnar I, Leko A, Palkovits M, Nagy GM, Usdin TB, Dobolyi A (2013) Thalamic neuropeptide mediating the effects of nursing on lactation and maternal motivation. Psychoneuroendocrinology 38:3070-3084.

Dekkers MP, Nikoletopoulou V, Barde YA (2013) Cell biology in neuroscience: death of developing neurons: new insights and implications for connectivity. J Cell Biol 203:385-393.

Dobolyi A (2009) Central amylin expression and its induction in rat dams. J Neurochem 111:1490-1500.

Dobolyi A (2011) Novel potential regulators of maternal adaptations during lactation: tuberoinfundibular peptide 39 and amylin. J Neuroendocrinol 23:1002-1008.

Dobolyi A, Palkovits M, Bodnar I, Usdin TB (2003) Neurons containing tuberoinfundibular peptide of 39 residues project to limbic, endocrine, auditory and spinal areas in rat. Neuroscience 122:1093-1105.

Duffy S, Lutz TA, Boyle CN (2018) Rodent models of leptin receptor deficiency are less sensitive to amylin. Am J Physiol Regul Integr Comp Physiol 315:R856-R865.

Duman RS, Nakagawa S, Malberg J (2001b) Regulation of adult neurogenesis by antidepressant treatment. Neuropsychopharmacology 25:836-844.

Duman RS, Malberg J, Nakagawa S (2001a) Regulation of adult neurogenesis by psychotropic drugs and stress. J Pharmacol Exp Ther 299:401-407.

Dunn-Meynell AA, Le Foll C, Johnson MD, Lutz TA, Hayes MR, Levin $\mathrm{BE}$ (2016) Endogenous $\mathrm{VMH}$ amylin signaling is required for full leptin signaling and protection from diet-induced obesity. Am J Physiol Regul Integr Comp Physiol 310:R355-365. 
Eiden S, Daniel C, Steinbrueck A, Schmidt I, Simon E (2002) Salmon calcitonin - a potent inhibitor of food intake in states of impaired leptin signalling in laboratory rodents. J Physiol 541:1041-1048.

Essner RA, Smith AG, Jamnik AA, Ryba AR, Trutner ZD, Carter ME (2017) AgRP neurons can increase food intake during conditions of appetite suppression and inhibit anorexigenic parabrachial neurons. J Neurosci 37:8678-8687.

Farr SA, Banks WA, Morley JE (2006) Effects of leptin on memory processing. Peptides 27:1420-1425.

Figlewicz DP (2016) Expression of receptors for insulin and leptin in the ventral tegmental area/substantia nigra (VTA/SN) of the rat: historical perspective. Brain Res 1645:68-70.

Friedman $J$ (2016) The long road to leptin. J Clin Invest 126:4727-4734

Garris DR (1989) Morphometric analysis of obesity (ob/ob)- and diabetes $(\mathrm{db} / \mathrm{db})$-associated hypothalamic neuronal degeneration in C57BL/KsJ mice. Brain Res 501:162-170.

Garza JC, Guo M, Zhang W, Lu XY (2008) Leptin increases adult hippocampal neurogenesis in vivo and in vitro. J Biol Chem 283:18238-18247.

Ghamari-Langroudi M, Srisai D, Cone RD (2011) Multinodal regulation of the arcuate/paraventricular nucleus circuit by leptin. Proc Natl Acad Sci U S A 108:355-360.

Ginhoux F, Greter M, Leboeuf M, Nandi S, See P, Gokhan S, Mehler MF, Conway SJ, et al. (2010) Fate mapping analysis reveals that adult microglia derive from primitive macrophages. Science 330:841-845.

Gloy VL, Lutz TA, Langhans W, Geary N, Hillebrand JJ (2010) Basal plasma levels of insulin, leptin, ghrelin, and amylin do not signal adiposity in rats recovering from forced overweight. Endocrinology 151:4280-4288.

Godfrey N, Borgland SL (2019) Diversity in the lateral hypothalamic input to the ventral tegmental area. Neuropharmacology:4-12.

Gokozan HN, Baig F, Corcoran S, Catacutan FP, Gygli PE, Takakura AC, Moreira TS, Czeisler C, et al. (2016) Area postrema undergoes dynamic postnatal changes in mice and humans. J Comp Neurol 524:1259-1269.

Grove KL, Allen S, Grayson BE, Smith MS (2003) Postnatal development of the hypothalamic neuropeptide $\mathrm{Y}$ system. Neuroscience 116:393-406.

Gurlo T, Kim S, Butler AE, Liu C, Pei L, Rosenberger M, Butler PC (2019) Pregnancy in human IAPP transgenic mice recapitulates beta cell stress in type 2 diabetes. Diabetologia 62:1000-1010.

Hardie L, Trayhurn P, Abramovich D, Fowler P (1997) Circulating leptin in women: a longitudinal study in the menstrual cycle and during pregnancy. Clin Endocrinol (Oxf) 47:101-106.

Hay DL, Chen S, Lutz TA, Parkes DG, Roth JD (2015) Amylin: pharmacology, physiology, and clinical potential. Pharmacol Rev 67:564-600

Herrera E (2000) Metabolic adaptations in pregnancy and their implications for the availability of substrates to the fetus. Eur J Clin Nutr 54(Suppl 1):S47-51.

Hilton JM, Chai SY, Sexton PM (1995) In vitro autoradiographic localization of the calcitonin receptor isoforms, $\mathrm{C} 1 \mathrm{a}$ and $\mathrm{C} 1 \mathrm{~b}$, in rat brain. Neuroscience 69:1223-1237

Huang CJ, Haataja L, Gurlo T, Butler AE, Wu X, Soeller WC, Butler PC (2007) Induction of endoplasmic reticulum stress-induced beta-cell apoptosis and accumulation of polyubiquitinated proteins by human islet amyloid polypeptide. Am J Physiol Endocrinol Metab 293:E1656-1662.

Ishii Y, Bouret SG (2012) Embryonic birthdate of hypothalamic leptinactivated neurons in mice. Endocrinology 153:3657-3667.

Johnson MD, Bouret SG, Dunn-Meynell AA, Boyle CN, Lutz TA, Levin BE (2016) Early postnatal amylin treatment enhances hypothalamic leptin signaling and neural development in the selectively bred diet-induced obese rat. Am J Physiol Regul Integr Comp Physiol 311:R1032-R1044.

Kamesh A, Black EAE, Ferguson AV (2018) The subfornical organ: a novel site for prolactin action. J Neuroendocrinol 30 e12613.

Kautzky-Willer A, Thomaseth K, Ludvik B, Nowotny P, Rabensteiner D, WaldhausI W, Pacini G, Prager R (1997) Elevated islet amyloid pancreatic polypeptide and proinsulin in lean gestational diabetes. Diabetes 46:607-614

Kinalski M, Sledziewski A, Telejko B, Straczkowski M, Kretowski A, Kinalska I (2004) Post-partum evaluation of amylin in lean patients with gestational diabetes mellitus. Acta Diabetol 41:1-4. Knopp RH, Herrera E, Freinkel N (1970) Carbohydrate metabolism in pregnancy. 8. Metabolism of adipose tissue isolated from fed and fasted pregnant rats during late gestation. J Clin Invest 49:1438-1446

Ladyman SR, Augustine RA, Grattan DR (2010) Hormone interactions regulating energy balance during pregnancy. $J$ Neuroendocrinol 22:805-817.

Ladyman SR, Grattan DR (2005) Suppression of leptin receptor messenger ribonucleic acid and leptin responsiveness in the ventromedial nucleus of the hypothalamus during pregnancy in the rat. Endocrinology 146:3868-3874.

Ladyman SR, Tups A, Augustine RA, Swahn-Azavedo A, Kokay IC, Grattan DR (2009) Loss of hypothalamic response to leptin during pregnancy associated with development of melanocortin resistance. J Neuroendocrinol 21:449-456.

Ladyman SR, Augustine RA, Scherf E, Phillipps HR, Brown $\mathrm{CH}$, Grattan DR (2016) Attenuated hypothalamic responses to alphamelanocyte stimulating hormone during pregnancy in the rat. $J$ Physiol 594:1087-1101.

Ladyman SR, Grattan DR (2004) Region-specific reduction in leptininduced phosphorylation of signal transducer and activator of transcription-3 (STAT3) in the rat hypothalamus is associated with leptin resistance during pregnancy. Endocrinology 145:3704-3711.

Ladyman SR, Khant Aung Z, Grattan DR (2018) Impact of pregnancy and lactation on the long-term regulation of energy balance in female mice. Endocrinology 159:2324-2336.

Lage M, Garcia-Mayor RV, Tome MA, Cordido F, Valle-Inclan F Considine RV, Caro JF, Dieguez C, et al. (1999) Serum leptin levels in women throughout pregnancy and the postpartum period and in women suffering spontaneous abortion. Clin Endocrinol (Oxf) 50:211-216.

Larsen L, Le Foll C, Dunn-Meynell AA, Levin BE (2016) IL-6 ameliorates defective leptin sensitivity in DIO ventromedial hypothalamic nucleus neurons. Am J Physiol Regul Integr Comp Physiol 311:R764-R770.

Le Foll C, Johnson MD, Dunn-Meynell AA, Boyle CN, Lutz TA, Levin BE (2015) Amylin-induced central IL-6 production enhances ventromedial hypothalamic leptin signaling. Diabetes 64:1621-1631.

Lee SM, Hay DL, Pioszak AA (2016) Calcitonin and amylin receptor peptide interaction mechanisms: insights into peptide-binding modes and allosteric modulation of the calcitonin receptor by receptor activity-modifying proteins. J Biol Chem 291:8686-8700.

Levin BE, Lutz TA (2017) Amylin and leptin: Co-regulators of energy homeostasis and neuronal development. Trends Endocrinol Metab 28:153-164.

Levin BE, Strack AM (2008) Diet-induced obesity in animal models and what they tell us about human obesity. In: Harvey J, Withers DJ, editors. Neurobiology of Obesity. Cambridge: Cambridge University Press. p. 164-195.

Levin BE, Dunn-Meynell AA, Balkan B, Keesey RE (1997) Selective breeding for diet-induced obesity and resistance in SpragueDawley rats. Am J Physiol 273:R725-R730.

Levin BE, Dunn-Meynell AA (2002) Reduced central leptin sensitivity in rats with diet-induced obesity. Am J Physiol 283:R941-R948.

Li X, Fan K, Li Q, Pan D, Hai R, Du C (2019) Melanocortin 4 receptormediated effects of amylin on thermogenesis and regulation of food intake. Diabetes Metab Res Rev 35 e3149.

Li Z, Kelly L, Heiman M, Greengard P, Friedman JM (2015) Hypothalamic amylin acts in concert with leptin to regulate food intake. Cell Metab 22:1059-1067.

Liberini CG, Boyle CN, Cifani C, Venniro M, Hope BT, Lutz TA (2016b) Amylin receptor components and the leptin receptor are co-expressed in single rat area postrema neurons. Eur J Neurosci 43:653-661. 
Liberini CG, Borner T, Boyle CN, Lutz TA (2016a) The satiating hormone amylin enhances neurogenesis in the area postrema of adult rats. Mol Metab 5:834-843.

Lledo PM, Valley M (2016) Adult olfactory bulb neurogenesis. Cold Spring Harb Perspect Biol 8.

Lutz TA, Mollet A, Rushing PA, Riediger T, Scharrer E (2001) The anorectic effect of a chronic peripheral infusion of amylin is abolished in area postrema/nucleus of the solitary tract (AP/NTS) lesioned rats. Int J Obes Relat Metab Disord 25:1005-1011.

Lutz TA, Le Foll C (2019) Endogenous amylin contributes to birth of microglial cells in arcuate nucleus of hypothalamus and area postrema during fetal development. Am J Physiol Regul Integr Comp Physiol 316:R791-R801.

Lutz TA, Coester B, Whiting L, Dunn-Meynell AA, Boyle CN, Bouret SG, Levin BE, Le Foll C (2018) Amylin selectively signals onto POMC neurons in the arcuate nucleus of the hypothalamus. Diabetes 67:805-817.

Markakis EA (2002) Development of the neuroendocrine hypothalamus. Front Neuroendocrinol 23:257-291.

Masuzaki H, Ogawa Y, Sagawa N, Hosoda K, Matsumoto T, Mise H, Nishimura H, Yoshimasa $Y$, et al. (1997) Nonadipose tissue production of leptin: leptin as a novel placenta-derived hormone in humans. Nat Med 3:1029-1033.

Mauvais-Jarvis F, Le May C, Tiano JP, Liu S, Kilic-Berkmen G, Kim $\mathrm{JH}$ (2017) The role of estrogens in pancreatic islet physiopathology. Adv Exp Med Biol 1043:385-399.

McNay DE, Briancon N, Kokoeva MV, Maratos-Flier E, Flier JS (2012) Remodeling of the arcuate nucleus energy-balance circuit is inhibited in obese mice. $\mathrm{J}$ Clin Invest 122:142-152.

Mietlicki-Baase EG, McGrath LE, Koch-Laskowski K, Krawczyk J, Reiner DJ, Pham T, Nguyen CTN, Turner CA, et al. (2017) Amylin receptor activation in the ventral tegmental area reduces motivated ingestive behavior. Neuropharmacology 123:67-79.

Mistry AM, Swick AG, Romsos DR (1997) Leptin rapidly lowers food intake and elevates metabolic rates in lean and ob/ob mice. J Nutr 127:2065-2072.

Mistry AM, Swick A, Romsos DR (1999) Leptin alters metabolic rates before acquisition of its anorectic effect in developing neonatal mice. Am J Physiol 277:R742-R747

Moon HS, Dincer F, Mantzoros CS (2013) Amylin-induced downregulation of hippocampal neurogenesis is attenuated by leptin in a STAT3/AMPK/ERK-dependent manner in mice. Diabetologia 56:627-634.

Mulder H, Myrsen-Axcrona U, Gebre-Medhin S, Ekblad E, Sundler F (1998) Expression of non-classical islet hormone-like peptides during the embryonic development of the pancreas. Microsc Res Tech 43:313-321.

Nilsson I, Johansen JE, Schalling M, Hokfelt T, Fetissov SO (2005) Maturation of the hypothalamic arcuate agouti-related protein system during postnatal development in the mouse. Brain Res Dev Brain Res 155:147-154.

Niswender KD, Morton GJ, Stearns WH, Rhodes CJ, Myers MG, Schwartz MW (2001) Intracellular signalling. Key enzyme in leptin-induced anorexia. Nature 413:794-795.

Ogawa A, Harris V, McCorkle SK, Unger RH, Luskey KL (1990) Amylin secretion from the rat pancreas and its selective loss after streptozotocin treatment. J Clin Invest 85:973-976.

Oomura Y, Hori N, Shiraishi T, Fukunaga K, Takeda H, Tsuji M, Matsumiya T, Ishibashi M, et al. (2006) Leptin facilitates learning and memory performance and enhances hippocampal CA1 longterm potentiation and CaMK II phosphorylation in rats. Peptides 27:2738-2749.

Padilla S, Carmody J, Zeltser L (2010) Pomc-expressing progenitors give rise to antagonistic neuronal populations in hypothalamic feeding circuits. Nat Med 16:403-405.

Pan W, Adams JM, Allison MB, Patterson C, Flak JN, Jones J, Strohbehn G, Trevaskis J, et al. (2018) Essential role for hypothalamic calcitonin receptorexpressing neurons in the control of food intake by leptin. Endocrinology 159:1860-1872.
Pan W, Allison MB, Sabatini P, Rupp A, Adams J, Patterson C, Jones JC, Olson DP, et al. (2019) Transcriptional and physiological roles for STAT proteins in leptin action. Mol Metab 22:121-131.

Park HK, Ahima RS (2015) Physiology of leptin: energy homeostasis, neuroendocrine function and metabolism. Metabolism 64:24-34.

Patterson CM, Bouret SG, Park S, Irani BG, Dunn-Meynell AA, Levin BE (2010) Large litter rearing enhances leptin sensitivity and protects selectively bred diet-induced obese (DIO) rats from becoming obese. Endocrinology 151:4270-4279.

Pazos P, Lima L, Casanueva FF, Dieguez C, Garcia MC (2013) Interleukin 6 deficiency modulates the hypothalamic expression of energy balance regulating peptides during pregnancy in mice. PLoS One 8 e72339.

Plows JF, Yu X, Broadhurst R, Vickers MH, Tong C, Zhang H, Qi H, Stanley JL, et al. (2017) Absence of a gestational diabetes phenotype in the LepRdb/+ mouse is independent of control strain, diet, misty allele, or parity. Sci Rep 7:45130.

Potes CS, Turek VF, Cole RL, Vu C, Roland BL, Roth JD, Riediger T, Lutz TA (2010a) Noradrenergic neurons of the area postrema mediate amylin's hypophagic action. Am J Physiol Regul Integr Comp Physiol 299:R623-631.

Potes CS, Lutz TA, Riediger T (2010b) Identification of central projections from amylin-activated neurons to the lateral hypothalamus. Brain Res 1334:31-44.

Potes CS, Lutz TA (2010) Brainstem mechanisms of amylin-induced anorexia. Physiol Behav 100:511-518.

Qi T, Christopoulos G, Bailey RJ, Christopoulos A, Sexton PM, Hay DL (2008) Identification of N-terminal receptor activity-modifying protein residues important for calcitonin gene-related peptide, adrenomedullin, and amylin receptor function. Mol Pharmacol 74:1059-1071.

Reiner DJ, Mietlicki-Baase EG, Olivos DR, McGrath LE, Zimmer DJ, Koch-Laskowski K, Krawczyk J, Turner CA, et al. (2017) Amylin acts in the lateral dorsal tegmental nucleus to regulate energy balance through gamma-aminobutyric acid signaling. Biol Psychiatry 82:828-838.

Riediger T, Schmid HA, Lutz T, Simon E (2001) Amylin potently activates AP neurons possibly via formation of the excitatory second messenger cGMP. Am J Physiol Regul Integr Comp Physiol 281:R1833-1843.

Riediger T, Zuend D, Becskei C, Lutz TA (2004) The anorectic hormone amylin contributes to feeding-related changes of neuronal activity in key structures of the gut-brain axis. Am J Physiol Regul Integr Comp Physiol 286:R114-122.

Rindi G, Terenghi G, Westermark G, Westermark P, Moscoso G, Polak JM (1991) Islet amyloid polypeptide in proliferating pancreatic B cells during development, hyperplasia, and neoplasia in humans and mice. Am J Pathol 138:1321-1334.

Roth JD, Hughes H, Kendall E, Baron AD, Anderson CM (2006) Antiobesity effects of the beta-cell hormone amylin in diet-induced obese rats: effects on food intake, body weight, composition, energy expenditure, and gene expression. Endocrinology 147:5855-5864.

Roth JD, Roland BL, Cole RL, Trevaskis JL, Weyer C, Koda JE, Anderson CM, Parkes DG, et al. (2008) Leptin responsiveness restored by amylin agonism in diet-induced obesity: Evidence from nonclinical and clinical studies. Proc Natl Acad Sci U S A 105:7257-7262.

Seeber RM, Smith JT, Waddell BJ (2002) Plasma leptin-binding activity and hypothalamic leptin receptor expression during pregnancy and lactation in the rat. Biol Reprod 66:1762-1767.

Sexton PM, Paxinos G, Kenney MA, Wookey PJ, Beaumont K (1994) In vitro autoradiographic localization of amylin binding sites in rat brain. Neuroscience 62:553-567.

Smith PM, Brzezinska P, Hubert F, Mimee A, Maurice DH, Ferguson AV (2016) Leptin influences the excitability of area postrema neurons. Am J Physiol Regul Integr Comp Physiol 310:R440-448.

Sousa C, Biber K, Michelucci A (2017) Cellular and molecular characterization of microglia: a unique immune cell population. Front Immunol 8:198. 
Steppan CM, Swick AG (1999) A role for leptin in brain development. Biochem Biophys Res Commun 256:600-602.

Stiles J, Jernigan TL (2010) The basics of brain development. Neuropsychol Rev 20:327-348.

Szabo ER, Cservenak M, Dobolyi A (2012) Amylin is a novel neuropeptide with potential maternal functions in the rat. FASEB $J$ 26:272-281.

Tilakaratne N, Christopoulos G, Zumpe ET, Foord SM, Sexton PM (2000) Amylin receptor phenotypes derived from human calcitonin receptor/RAMP coexpression exhibit pharmacological differences dependent on receptor isoform and host cell environment. J Pharmacol Exp Ther 294:61-72.

Tolcos M, Tikellis C, Rees S, Cooper M, Wookey P (2003) Ontogeny of calcitonin receptor mRNA and protein in the developing central nervous system of the rat. J Comp Neurol 456:29-38.

Trevaskis JL, Coffey T, Cole R, Lei C, Wittmer C, Walsh B, Weyer C, Koda J, et al. (2008) Amylin-mediated restoration of leptin responsiveness in diet-induced obesity: magnitude and mechanisms. Endocrinology 149:5679-5687.

Trevaskis JL, Parkes DG, Roth JD (2010) Insights into amylin-leptin synergy. Trends Endocrinol Metab 21:473-479.

Trevaskis JL, Wittmer C, Athanacio J, Griffin PS, Parkes DG, Roth JD (2016) Amylin/leptin synergy is absent in extreme obesity and not restored by calorie restriction-induced weight loss in rats. Obes Sci Pract 2:385-391.

Turek VF, Trevaskis JL, Levin BE, Dunn-Meynell AA, Irani B, Gu G, Wittmer C, Griffin PS, et al. (2010) Mechanisms of amylin/leptin synergy in rodent models. Endocrinology 151:143-152.
Udagawa J, Hashimoto R, Hioki K, Otani H (2006) The role of leptin in the development of the cortical neuron in mouse embryos. Brain Res 1120:74-82.

Vaisse C, Halaas JL, Horvath CM, Darnell Jr JE, Stoffel M, Friedman JM (1996) Leptin activation of Stat3 in the hypothalamus of wildtype and ob/ob mice but not db/db mice. Nat Gen 14:95-97.

van Rossum D, Menard DP, Fournier A, St-Pierre S, Quirion R (1994) Autoradiographic distribution and receptor binding profile of [125I] Bolton Hunter-rat amylin binding sites in the rat brain. J Pharmacol Exp Ther 270:779-787.

Vanhaesebroeck B, Stephens L, Hawkins P (2012) PI3K signalling: the path to discovery and understanding. Nat Rev Mol Cell Biol 13:195-203.

Villar J, Cogswell M, Kestler E, Castillo P, Menendez R, Repke JT (1992) Effect of fat and fat-free mass deposition during pregnancy on birth weight. Am J Obstet Gynecol 167:1344-1352.

Yook JS, Rakwal R, Shibato J, Takahashi K, Koizumi H, Shima T, Ikemoto MJ, Oharomari LK, et al. (2019) Leptin in hippocampus mediates benefits of mild exercise by an antioxidant on neurogenesis and memory. Proc Natl Acad Sci U S A 116:10988-10993.

Young A (2005) Tissue expression and secretion of amylin. Adv Pharmacol 52:19-45.

Zeng Z, Liu F, Li S (2017) Metabolic adaptations in pregnancy: a review. Ann Nutr Metab 70:59-65.
1316

1317

1318

1319

1320

1321

1322

1323

1324

1325

1326

1327

1328

1329

1330

1331

1332

1333

1334

1335

1336

1337

1338

1339

1340

(Received 20 July 2019, Accepted 21 November 2019)

(Available online $x x x x$ ) 